\title{
Control of Breathing by Raphe Obscurus Serotonergic Neurons in Mice
}

\author{
Seth D. DePuy, Roy Kanbar, Melissa B. Coates, Ruth L. Stornetta, and Patrice G. Guyenet \\ Department of Pharmacology, University of Virginia, Charlottesville, Virginia 22908
}

We used optogenetics to determine the global respiratory effects produced by selectively stimulating raphe obscurus (R0) serotonergic neurons in anesthetized mice and to test whether these neurons detect changes in the partial pressure of $\mathrm{CO}_{2}$, and hence function as central respiratory chemoreceptors. Channelrhodopsin-2 (ChR2) was selectively ( $\sim 97 \%)$ incorporated into $\sim 50 \%$ of R0 serotonergic neurons by injecting AAV2 DIO ChR2-mCherry (adeno-associated viral vector double-floxed inverse open reading frame of ChR2$m C h e r r y)$ into the RO of ePet-Cre mice. The transfected neurons heavily innervated lower brainstem and spinal cord regions involved in autonomic and somatic motor control plus breathing but eschewed sensory related regions. Pulsed laser photostimulation of ChR2transfected serotonergic neurons increased respiratory frequency (fR) and diaphragmatic EMG (dEMG) amplitude in relation to the duration and frequency of the light pulses (half saturation, $1 \mathrm{~ms} ; 5-10 \mathrm{~Hz}$ ). dEMG amplitude and fR increased slowly (half saturation after $10-15 \mathrm{~s}$ ) and relaxed monoexponentially (tau, $13-15 \mathrm{~s}$ ). The breathing stimulation was reduced $\sim 55 \%$ by methysergide (broad spectrum serotonin antagonist) and potentiated $(\sim 16 \%)$ at elevated levels of inspired $\mathrm{CO}_{2}(8 \%)$. RO serotonergic neurons, identified by their entrainment to short light pulses (threshold, $0.1-1 \mathrm{~ms}$ ) were silent (nine cells) or had a low and regular level of activity $(2.1 \pm 0.4 \mathrm{~Hz} ; 11$ cells) that was not synchronized with respiration. These and nine surrounding neurons with similar characteristics were unaffected by adding up to $10 \% \mathrm{CO}_{2}$ to the breathing mixture. In conclusion, $\mathrm{R} 0$ serotonergic neurons activate breathing frequency and amplitude and potentiate the central respiratory chemoreflex but do not appear to have a central respiratory chemoreceptor function.

\section{Introduction}

The pontomedullary region contains several clusters of serotonergic neurons with distinct physiological roles. Raphe magnus innervates primarily the dorsal horn of the spinal cord and seems implicated predominantly in sensory control, whereas raphe pallidus and the parapyramidal region (B6 group) target primarily the intermediolateral cell column and ventral horn and are probably involved in thermoregulation by way of skin blood flow control, brown fat thermogenesis, and shivering (Mason, 2001; Madden and Morrison, 2006). The raphe obscurus, a midline structure that extends throughout the medulla oblongata, is suspected to play a particularly prominent role in facilitating respiratory, autonomic, and somatic motor outflows (Jacobs et al., 2002).

Innumerable studies describe the effects of serotonin on neurons known or presumed to control various aspects of breathing, but the global contribution of specific subsets of serotonergic neurons to breathing is uncertain. The best approximation so far has been obtained by examining the effect produced by nonselective stimulation of the raphe with amino acids, (Ptak et al., 2009), but this method lacks selectivity given that the somatodendritic domain of medullary serotonergic neurons overlaps greatly with

Received Sept. 3, 2010; revised Nov. 11, 2010; accepted Dec. 6, 2010.

This work was supported by National Institutes of Health Grants HL28785 and HL74011 to P.G.G. and 1F32HL096280-01 to S.D.D.

Correspondence should be addressed to Dr. Patrice G. Guyenet, University of Virginia Health System, P.0. Box 800735, 1300 Jefferson Park Avenue, Charlottesville, VA 22908-0735. E-mail: pgg@virginia.edu.

DOI:10.1523/JNEUROSCI.4639-10.2011

Copyright $\odot 2011$ the authors $\quad 0270-6474 / 11 / 311981-10 \$ 15.00 / 0$ that of many other neurons. The present study focuses on the specific contribution of raphe obscurus serotonergic neurons to respiration and has three primary objectives. The first is to analyze comprehensively the projections of raphe obscurus serotonergic neurons. The second is to determine the global respiratory effects produced by stimulating these serotonergic neurons selectively in vivo. The third is to identify the discharge properties of the serotonergic neurons in vivo and to test the theory that these cells are central chemoreceptors (Hodges and Richerson, 2010), requiring that they be responsive to increases in $\mathrm{CNS} \mathrm{PCO}_{2}$ in vivo (Guyenet et al., 2010).

Our approach to each question relied on channelrhodopsin-2 (ChR2) optogenetics. ChR2 was incorporated into the serotonergic neurons by injecting adeno-associated viral vector doublefloxed inverse open reading frame (AAV2 DIO) ChR2-mCherry (Cardin et al., 2009) into the raphe obscurus of ePet-Cre transgenic mice in which the Cre recombinase is exclusively expressed by serotonergic neurons (Scott et al., 2005). Histological inspection of the tissue indicated that ChR2 was specifically expressed by serotonergic neurons and that these cells were mostly confined to raphe obscurus. The fusion protein ChR2-mCherry is membrane associated and eventually covers the entire surface of the neurons including axons and terminals (Abbott et al., 2009b; Gradinaru et al., 2010). This property allowed us to map the projection fields of the ChR2-expressing serotonergic neurons. Pulsed laser light was used to activate ChR2-expressing raphe obscurus serotonergic neurons selectively in vivo and assess the effects of this stimulation on breathing. Finally, we identified ChR2-expressing serotonergic neurons in vivo by their character- 
istic response to submillisecond light pulses (Nagel et al., 2003; Lima et al., 2009; Abbott et al., 2009b; Cardin et al., 2010), and we tested their reactivity to elevation of brain $\mathrm{PCO}_{2}$.

\section{Materials and Methods}

Animal use was in accordance with guidelines approved by the University of Virginia Animal Care and Use Committee. All experiments reported herein were done on $18 \mathrm{ePet}$-Cre mice of either sex ( 12 females, 6 males) that were 17-27 weeks old when subjected to AAV injections into the brainstem and 27-32 weeks old at the time of recording (females, 23-27 g; males, $30-36$ g; average postsurgery duration, $\sim 30 \mathrm{~d}$ ). The ePet-Cre mice were kindly provided by E. S. Deneris (Case Western Reserve University, Cleveland, $\mathrm{OH}$ ) and bred onto a C57B6/J background (Scott et al., 2005).

Viral vector design and microinjection. The viral construct (adenoassociated viral vector double-floxed inverse open reading frame ChR2$m$ Cherry) (Cardin et al., 2009) was kindly provided by K. Deisseroth (Stanford University, Stanford, CA). This construct features an enhanced version of the photosensitive cationic channel channelrhodopsin-2 (ChR2 H134R) fused to the reporter mCherry and under the control of the $\mathrm{eF} 1 \alpha$ promoter. The eF1 $\alpha$-ChR2-mCherry sequence is flanked by double loxP sites. The construct was amplified and sent to the University of North Carolina Vector Core (Chapel Hill, NC) for virus production of AAV2 (titer, $10^{12}$ virus molecules per milliliter). Mice were anesthetized with a mixture of ketamine $(100 \mathrm{mg} / \mathrm{kg})$ and dexmedetomidine $\mathrm{HCl}$ (Dexdomitor, $0.2 \mathrm{mg} / \mathrm{kg}$ ) injected intraperitoneally. They were placed on a stereotaxic apparatus with the head bent forward $\sim 30^{\circ}$ and were maintained at $37^{\circ} \mathrm{C}$ with a servocontrolled heating pad. After dividing or separating the neck muscles on the midline, a small incision was made in the atlanto-occipital membrane to reveal the caudal tip of the area postrema. The AAV2 was injected through a glass pipette $(25 \mu \mathrm{m}$ outside diameter at the tip) connected to an electronically controlled pressure valve (Picospritzer). The pipette was inserted at a $30^{\circ}$ angle toward the head of the mouse through the caudal end of the area postrema to a depth of $1.7 \mathrm{~mm}$. Short pressure pulses (3-6 ms) were used to inject between 130 and $200 \mathrm{nl}$ of virus over $10 \mathrm{~min}$. The wound was closed in two layers (muscles and skin). The mice were administered an antibiotic (ampicillin, $125 \mathrm{mg} / \mathrm{kg}$ ) and an analgesic (ketoprofen, $4 \mathrm{mg} / \mathrm{kg}$ ), and then atipemazole $2 \mathrm{mg} / \mathrm{kg}$ (Antisedan, an $\alpha$-2-adrenergic antagonist) to reverse the sedative effect of dexmedetomidine. The mice were then placed in a humidified $37^{\circ} \mathrm{C}$ environment until they fully recovered consciousness and were finally transferred to a regular cage. The mice received a second round of antibiotic and analgesic treatment the next day before being returned to the vivarium.

In vivo electrophysiology. Anesthesia was induced with ketaminedexmedetomidine (see above), and the mouse was placed in a modified Kopf stereotaxic apparatus (model 926) with the bite bar of the adaptor set at $-1 \mathrm{~mm}$. This adaptor was also outfitted with a nose mask (Kopf model 907) through which the breathing mixture was delivered (100\% oxygen during surgery, pure oxygen with various concentrations of isoflurane during recording). An opening was drilled through the occipital plate $1.2 \mathrm{~mm}$ caudal to the occipital-parietal suture through which the optical fiber and a glass recording electrode could be inserted. Two thin Teflon-coated silver wires with bared tips forming a $2 \mathrm{~mm}$ hook were inserted through the lateral edge of the diaphragm on the right side of the animals using 25 gauge, $5 / 8$ inch hypodermic needles. The electrode tips were inserted no more than $2-4 \mathrm{~mm}$ apart to minimize the electrocardiogram (EKG) artifact.

In experiments in which no unit recording was done, photostimulation of ChR2-transfected neurons was accomplished by inserting a 200 $\mu \mathrm{m}$ optical fiber vertically 5 to $5.5 \mathrm{~mm}$ below the cerebellar surface (coordinates, midline and 1.2 to $1.3 \mathrm{~mm}$ caudal to the parietal-occipital suture, i.e., lambda). In experiments in which unit recordings were done, the optical fiber was inserted at a $15^{\circ}$ angle toward the midline, $1.4 \mathrm{~mm}$ lateral to the midline to a depth of $5.5 \mathrm{~mm}$, and the recording electrode was introduced vertically (coordinates, midline and 1.1 to $1.5 \mathrm{~mm}$ caudal to lambda). Photoactivated raphe units were found at a depth of 5.1 to 5.8 below the cerebellar surface and exclusively on the midline. The light source was a diode-pumped $473 \mathrm{~nm}$ blue laser (CrystaLaser model BC473-060-M) controlled by a function generator (Grass Instruments) to generate light pulses of various durations ( $50 \mu$ s to $20 \mathrm{~ms}$ ) and frequencies $(1$ to $20 \mathrm{~Hz})$. The power output was measured at the tip of the fiberoptic with a light meter (Thorlabs) and preset at precisely $9 \mathrm{~mW}$ when the laser was activated in continuous mode. This power output was defined empirically in our previous experiments with ChR2-transfected brainstem neurons (Abbott et al., 2009a,b). It was also found suitable for raphe neurons based on the reproducibility of the changes in single raphe neuron activity and diaphragmatic EMG (dEMG) elicited by successive stimulation episodes and the absence of histological lesion indicative of heat damage. A second pulsed laser (Shanghai Laser and Optics Century) activated by the same function generator (see above) was used in control experiments to deliver $532 \mathrm{~nm}$ light pulses (green light). In these experiments, the power output was measured at the tip of the fiberoptic using the above-mentioned light meter. Power output was preset at $9 \mathrm{~mW}$ for both laser sources.

The surgical procedures were completed in $<30 \mathrm{~min}$. Recordings were made for the next $90 \mathrm{~min}$ when no unit recordings were obtained, or the next $4 \mathrm{~h}$ when unit recordings were sought. During recording, anesthesia was maintained by addition of one or two boosters of ketamine-dexmedetomidine (sufficient for an additional $1 \mathrm{~h}$ ) followed by incremental concentrations of isoflurane from 0.2 to $1 \%$ as needed to eliminate hindlimb withdrawal reflexes. dEMG (bandpass, 30-3000 Hz) and singleunit recordings (5-8 $\mathrm{M} \Omega$ glass pipettes filled with $2 \mathrm{M} \mathrm{NaCl}$; bandpass, $300-3000 \mathrm{~Hz}$ ) were recorded conventionally. To elicit the chemoreflex, $\mathrm{CO}_{2}$ was added to the breathing mixture, and the concentration of $\mathrm{CO}_{2}$ within the breathing mask was monitored with a capnometer. All analog data were acquired on a computer via a Micro1401 digitizer (Cambridge Electronic Design) and were processed off-line using Spike 5 software (Cambridge Electronic Design). Usually, dEMG was digitally filtered to further minimize the EKG artifact, rectified, and integrated (time constant, $0.03 \mathrm{~s}$ ). The integrated signal was used to determine the respiratory rate $\left(\right.$ minutes $\left.^{-1}\right)$ and the respiratory amplitude using an automatic peak detection feature. Respiratory amplitude was expressed in arbitrary units, zero representing the level observed between inspiratory bursts. The ascending phase of the inspiratory burst was used as trigger for perievent histograms of single-unit activity. This analysis was designed to test whether the activity of the recorded serotonergic neurons fluctuated in synchrony with the respiratory cycle (for details, see Guyenet et al., 2005).

Histology. After each experiment in vivo, mice were deeply anesthetized with pentobarbital and perfused transcardially with $4 \%$ paraformaldehyde. The brain and spinal cord were extracted and kept in $4 \%$ paraformaldehyde for $24-48 \mathrm{~h}$. Brains were cut at room temperature on a vibrating microtome (Leica) into $30 \mu \mathrm{m}$ transverse sections and stored at $-20^{\circ} \mathrm{C}$ before further processing. All histological procedures were performed on free-floating sections. ChR2-mCherry was detected with rabbit anti-dsRed (1:500; Clontech) followed by donkey-anti-rabbit IgGCy3 (1:200; Jackson ImmunoResearch Laboratories). Tryptophan hydroxylase was detected by immunohistochemistry using mouse antitryptophan hydroxylase (1:1000; Sigma) followed by donkey anti-mouse Alexa 488 IgG (1:200; Invitrogen). Cholinergic neurons were identified using goat anti-choline acetyltransferase (ChAT) (1:100; Millipore Bioscience Research Reagents) followed by donkey anti-goat DyLight 649 (1:200; Jackson ImmunoResearch).

Sections were mounted onto glass slices, dehydrated through a series of graded alcohols and xylenes, and covered with DPX mounting medium (Fluka/Sigma-Aldrich). The histological material was examined and photographed using a Zeiss Axioimager.Z1 (Carl Zeiss Microimaging) with a Zeiss Axiocam MRc digital camera (basic resolution, $1388 \times$ 1040 pixels). ChR2-transfected and untransfected serotonergic neurons were plotted using the Neurolucida computer-assisted graphing software as described previously (Stornetta et al., 2002). Neurons were counted in a one-in-six series of 30- $\mu \mathrm{m}$-thick transverse sections that encompassed the transfected brain area (from 3-10 sections/mouse).

Statistics. All values are presented as mean \pm SEM. Statistical significance was set at $p<0.05$. Paired and unpaired $t$ tests and one-way repeated measures ANOVAs were used as required. The Tukey-Holm- 

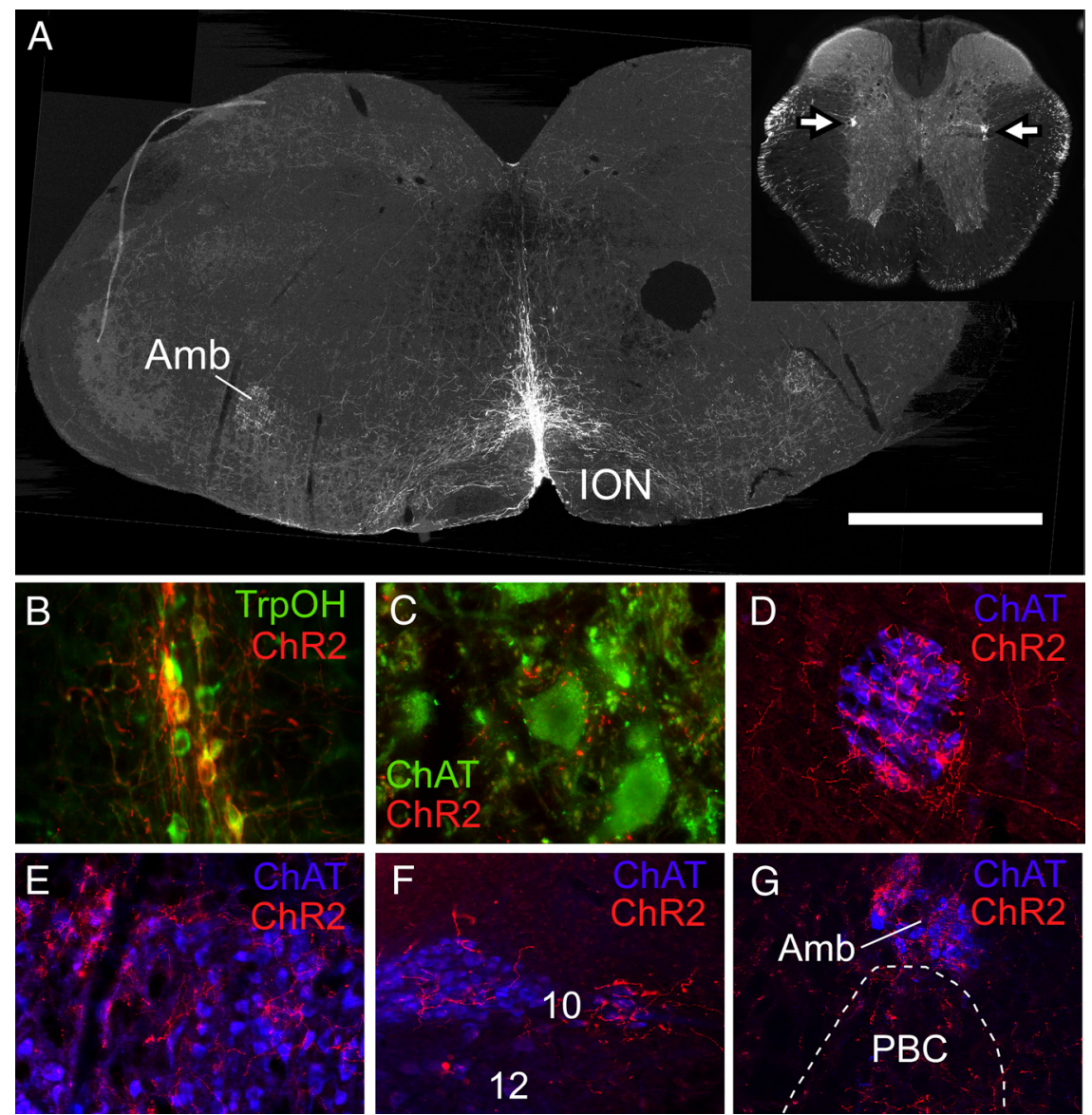

Figure 1. ChR2-mCherry expression in raphe obscurus neurons and their axonal projections. $A$, Transverse section of medulla oblongata $6.9 \mathrm{~mm}$ caudal to bregma showing location of $\mathrm{m}$-Cherry immunoreactivity (Cy3 epifluorescence) ChR2-mCherry-expressing neurons were confined to the raphe, primarily raphe obscurus. The circular hole located on the right side of the brain was punched just before sectioning for purposes of orientation. Inset, A coronal section of thoracic spinal cord; arrows point to a dense projection to the intermediolateral cell column containing the sympathetic preganglionic neurons. Amb, Nucleus ambiguus; ION, inferior olivary nucleus. B, Virtually all ChR2-mCherry-expressing neurons (red Cy3 fluorescence) in raphe obscurus were immunoreactive for tryptophan hydroxylase (Trp0H, green Alexa 488 fluorescence) (overlap, yellow-orange). C, Close appositions between mCherry-immunoreactive axon varicosities or terminals (red Cy3 fluorescence) and putative phrenic motor neurons (ChAT positive; green Alexa 488 fluorescence). D-F, Dense innervation of brain autonomic and somatic motor neurons. $\boldsymbol{D}$, Compact nucleus ambiguus. $\boldsymbol{E}$, Facial motor nucleus. $\boldsymbol{F}$, Dorsal motor nucleus of the vagus (10) and hypoglossal nucleus (12). $\boldsymbol{G}$, Heavy innervation of nucleus ambiguus and immediately adjacent pre-Bötzinger complex (PBC). Scale bars: $\boldsymbol{A}, 1 \mathrm{~mm} ; \boldsymbol{B}, 125 \mu \mathrm{m} ; \boldsymbol{C}, 80 \mu \mathrm{m} ; \boldsymbol{D}-\mathbf{G}, 250 \mu \mathrm{m}$.
Sidak method was used for all pairwise comparisons. If the data were not normally distributed, the Wilcoxon signed rank test for paired samples or the Friedman repeated measures ANOVA on ranks was used. Friedman repeated measures ANOVA on ranks was used to analyze the effects of $\mathrm{CO}_{2}$ on unit activity because the discharge rates were not normally distributed.

\section{Results}

\section{Selective targeting of $\mathrm{ChR} 2$ to} serotonergic neurons

The number and anatomical location of the ChR2-mCherry-expressing neurons was determined in 14 mice in which physiological recordings were successful. In six mice, ChR2-expressing neurons were confined to the raphe obscurus (Fig. $1 A$ ). In the other eight mice, smaller numbers of ChR2-expressing neurons were present in raphe pallidus, identified as a collection of small neurons located between the pyramidal tracts. Some neurons were present dorsal to the pyramidal tracts in four mice at levels rostral to the caudal end of the facial motor nucleus, a region that belongs to raphe magnus. In one mouse, labeled neurons were also present in the parapyramidal region on one side. The average rostrocaudal distribution of ChR2-expressing neurons for all 14 mice is shown in Figure 2 according to their location (raphe obscurus, raphe pallidus, and raphe magnus). Raphe obscurus proper clearly contained the most ChR2expressing neurons with peak cell density $6.9 \mathrm{~mm}$ behind bregma (Paxinos and Franklin, 2004).

Based on a systematic inspection of eight mice in which a one-in-six series of $30 \mu \mathrm{m}$ sections were reacted for immunohistochemical detection of tryptophan hydroxylase and mCherry, the vast majority of the ChR2-expressing neurons were serotonergic $(97 \pm 1 \%$; $75 \pm 9$ ChR2-

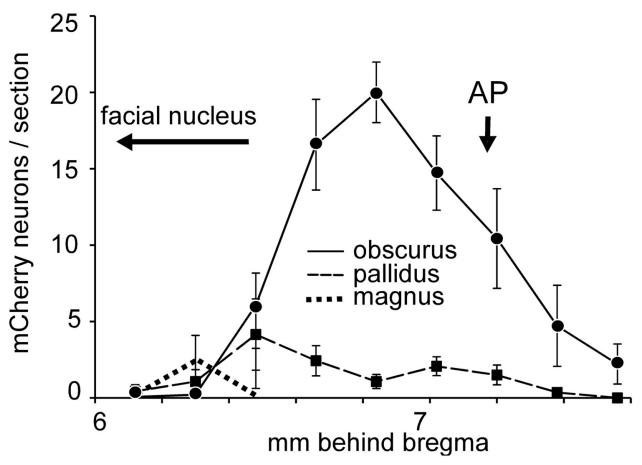

Figure 2. Distribution of ChR2-expressing neurons in brainstem raphe nuclei in $14 \mathrm{ePet}-\mathrm{Cre}$ mice transfected with ChR2-AAV2. Graph represents the mean \pm SE number of neurons counted per transverse section within raphe obscurus, pallidus, and magnus at the bregma levels shown on the abscissa. AP, Area postrema. Bregma levels follow Paxinos and Franklin (2004). positive neurons counted per mouse; range, 41-121 neurons) (Fig. $1 B$ ). In the raphe areas where ChR2-transfected neurons were observed, $48 \pm 7 \%$ of all the serotonergic neurons expressed the transgene.

\section{Projections of raphe obscurus serotonergic neurons}

The projections of raphe obscurus serotonergic neurons were examined in animals that had cell somas positive for ChR2mCherry transgene confined to this nucleus $(N=6)$. The densest projections were to motor neurons throughout the brainstem and spinal cord including putative phrenic motor neurons in the cervical cord between C4-C7 (Fig. 1C), the entire extent of the nucleus ambiguus (Fig. $1 D, G$ ), the facial motor nucleus (Fig. $1 E$ ), the dorsal motor nucleus of the vagus (Fig. $1 F$ ), and to a lesser extent the hypoglossal motor nucleus (Fig. $1 F$ ) and the trigeminal motor nucleus (data not shown). Ventral horn motor neurons were innervated throughout the entire length of the spinal cord (cervical to lumbar; sacral segments not examined). An- 
A

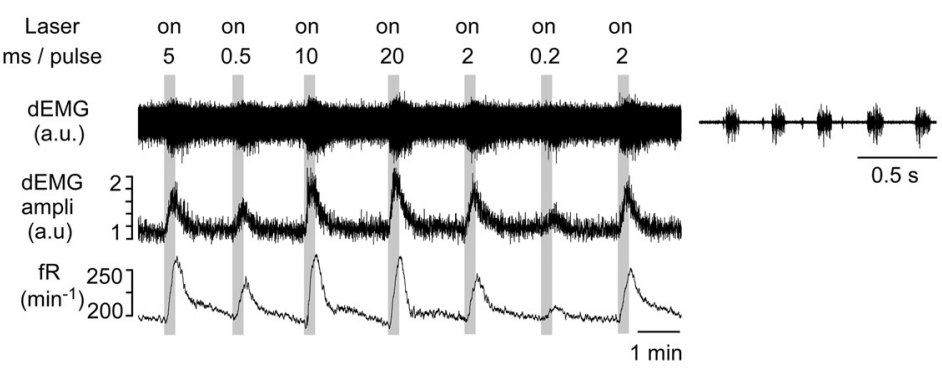

$\mathrm{B}$

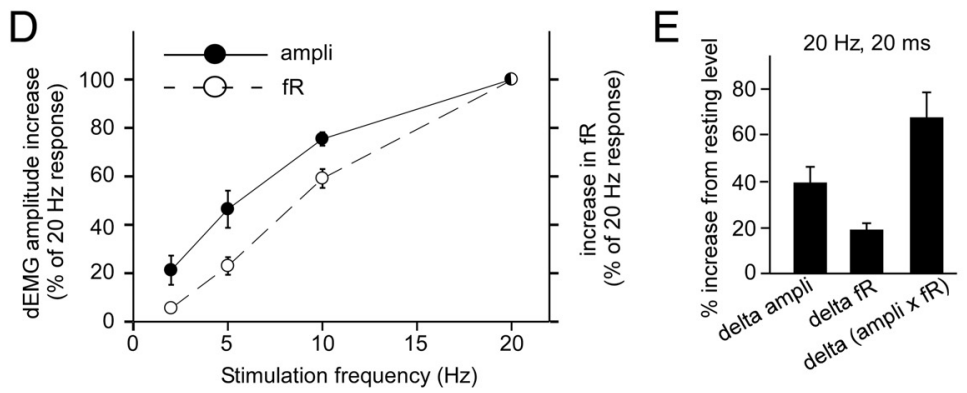

G

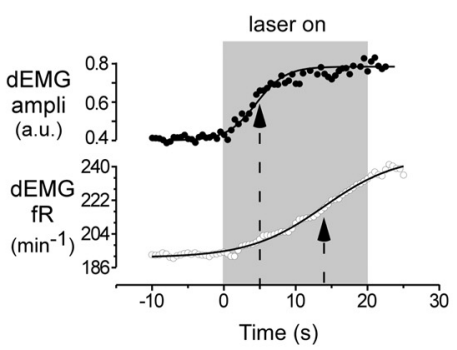

$\mathrm{H}$

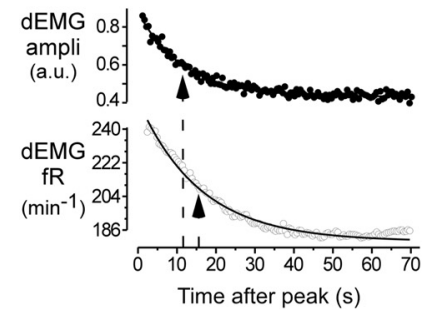

Figure 3. Breathing stimulation elicited by photostimulating ChR2-transfected raphe obscurus serotonergic neurons. $\boldsymbol{A}$, Increase in dEMG amplitude (ampli) and breathing frequency (fR) elicited by a $30 \mathrm{~s}$ train of $10 \mathrm{~ms}$ pulse duration, $20 \mathrm{~Hz}$ light pulses in one mouse. Top trace, Raw dEMG signal; higher-resolution excerpt at right. Middle trace, Amplitude of rectified and integrated dEMG presented in arbitrary units (a.u.). Bottom trace, Breathing frequency ( $\mathrm{fR}$, in minutes ${ }^{-1}$ ). In subsequent panels, the peak amplitude of each integrated dEMG burst is shown as dEMG amplitude. $\boldsymbol{B}$, Effect of pulse duration on the breathing increase evoked by raphe obscurus stimulation delivered at $20 \mathrm{~Hz}$ for $30 \mathrm{~s}$ (average of 3 mice). $\boldsymbol{C}$, Effect of stimulation frequency on the breathing response to 20 ms light pulses delivered for 30 s in one mouse. Top trace, Amplitude of rectified and integrated dEMG. Bottom trace, Respiratory frequency. $\boldsymbol{D}$, Effect of stimulation frequency on the breathing response to $20 \mathrm{~ms}$ light pulses delivered for $30 \mathrm{~s}$ (average of 5 mice). $\boldsymbol{E}$, Mean increase (delta) in breathing rate (fR) and diaphragmatic EMG amplitude expressed as percentage of resting values (mean of 11 mice). The product of the two, an index of the overall increase of lung ventilation, is also shown. $\boldsymbol{F}$, Amplitude (top) and frequency response to raphe stimulation (10 $\mathrm{Hz}, 20 \mathrm{ms)}$ in one mouse shown with expanded time scale. $\mathbf{G}$, Amplitude and frequency response at onset of raphe obscurus photostimulation ( $20 \mathrm{~Hz}, 10 \mathrm{~ms}$ pulses; $30 \mathrm{~s} \mathrm{train)}$ from three or four consecutive trials in the same mouse. The data points are fitted to a Boltzmann sigmoid equation used to determine the half-maximum response time; the average $\mathrm{T}_{50}$ is indicated by arrows. $\boldsymbol{H}$, Relaxation (fR and amplitude) after a 30 s train of $20 \mathrm{~Hz}, 10 \mathrm{~ms}$ stimuli. The curves are well fit by a single exponential from which a time constant was determined (arrows).

other striking projection was to the intermediolateral column and intermediomedial region around the central canal throughout the length of the thoracic and upper lumbar spinal cord (Fig. $1 A$, inset). The ventral lateral medulla also received moderate projections throughout, including the major site for respiratory rhythm generation, the pre-Bötzinger complex (Fig. $1 G$ ). Sparse projections were noted in the nucleus of the solitary tract and the parabrachial nucleus (lateral dorsal and crescent portions). Areas without projections included the superficial laminae of the dorsal horn of the spinal cord (all segments) as well as the locus ceruleus and the spinal trigeminal nuclei. No projections were observed rostral to the pons. Given that less than half of the serotonergic neurons were transfected, some of the projections of raphe obscurus may have been missed.

\section{Photostimulation of ChR2-transfected raphe neurons activates breathing}

Photostimulation of ChR2-transfected raphe neurons increased amplitude of the dEMG and the respiratory frequency (fR) in spontaneously breathing mice (Fig. $3 A$ ). The magnitude of the response depended on the duration and on the frequency of the light pulses. At a fixed test frequency of $20 \mathrm{~Hz}$, half-maximal responses for both amplitude and frequency required pulse durations of $0.5 \mathrm{~ms}$ and maximum responses were obtained with 20 ms pulses (Fig. $3 A, B$ ). At a fixed pulse duration of $20 \mathrm{~ms}$, threshold responses were observed at around $2 \mathrm{~Hz}$ and saturation near $20 \mathrm{~Hz}$ (Fig. 3C,D). The amplitude response was always monophasic with slow and gradual onset (Fig. $3 F$ ). The onset kinetics were best described by a sigmoid (Boltzmann) equation ( $y=A 2+$ $\left.\left[(A 1-A 2) /\left(1+\exp \left(x-x_{0}\right) / d x\right)\right]\right)$ (Figure 3G, top curve) with half-maximum response, $\mathrm{T}_{50}, 10.6 \pm 1.3 \mathrm{~ms}$ after the onset of the photostimulus and saturation after 20 to $30 \mathrm{~s}$ of continuous stimulation when $10-20 \mathrm{~Hz}, 20 \mathrm{~ms}$ trains were used (11 mice). The frequency response developed more slowly than the amplitude response and the respiratory rate continued to increase for up to $10 \mathrm{~s}$ after the end the stimulus train (Fig. $3 F$ ). The ascending phase of the frequency response was also best fit by a Boltzmann sigmoid equation. The $\mathrm{T}_{50}(15.8 \pm 0.7 \mathrm{~s}$ after onset of the photostimulus) was longer for the frequency response than the corresponding value for the above-mentioned amplitude response ( $p<0.05$; paired $t$ test; 11 mice) (Fig. $3 G$ ). The amplitude and the frequency responses decayed monoexponentially after the end of 
the photostimulus (dEMG amplitude) or response peak (respiratory rate) with approximately similar time constants $[14 \pm 1.7 \mathrm{~s}$ for dEMG amplitude, $16.7 \pm 1.2 \mathrm{~s}$ for frequency; not significant (NS) by paired $t$ test; $N=11$ ] (Fig. $3 H$ ). A long (up to $1 \mathrm{~min}$ ) period of slightly below baseline breathing frequency was often observed after the most intense stimuli [i.e., combination of long pulses $(10-20 \mathrm{~ms})$ and high frequency $(10-20 \mathrm{~Hz})]$ (Fig. $3 F)$. This undershoot was probably caused by the transient hypocapnia produced by the preceding hyperventilation.

Raphe obscurus photostimulation produced no effect in ePetCre mice that had not received injections of ChR2-mCherry AAV2 $(N=2)$, even when maximally effective stimulation parameters were used ( $9 \mathrm{~mW} ; 20 \mathrm{~ms} ; 20 \mathrm{~Hz} ; 60 \mathrm{~s}$ trains). In two ePet-Cre mice that had received injections of ChR2-mCherry AAV2, photostimulation of raphe obscurus with $532 \mathrm{~nm}$ light $(20$ $\mathrm{Hz} ; 10 \mathrm{~ms} ; 30 \mathrm{~s}$ trains; $9 \mathrm{~mW}$ ) produced a greatly attenuated response, whereas the usual robust respiratory response to 473 $\mathrm{nm}$ light (same parameters) was elicited (percentage increase in the double product of frequency and amplitude elicited by 473 nm light, 91 and 97\%; corresponding values in response to 532 nm light, 29 and 21\%, respectively). The first control experiment indicated that the breathing response caused by $473 \mathrm{~nm}$ light could not have been caused by the heat generated by the light. The spectral selectivity of the response (much greater response with 473 than $532 \mathrm{~nm}$ light; second control experiment) was consistent with the notion that the breathing response to photostimulation was attributable to the activation of channelrhodopsin-2 (Zhang et al., 2006).

On average (16 AAV-transfected mice), raphe stimulation using near maximally effective parameters $(20 \mathrm{~Hz} ; 10-20$ ms pulses; $30-40 \mathrm{~s}$ trains) increased dEMG amplitude by $42 \pm 6 \%$ (range, $8-93 \%$ ), breathing frequency by $19 \pm 2 \%$ (range, $2.8-44 \%$, corresponding to an increase in breathing rate of $34 \pm 5 \mathrm{~min}^{-1}$ from a resting level of $175 \pm 12 \mathrm{~min}^{-1}$ ), and the double product (amplitude by frequency, a parameter denoting overall magnitude of inspiratory efforts) by $70 \pm 9 \%$ (range, $16-141 \%$ ). The breathing stimulation was the same in males and females (percentage increase in double product, $66 \pm 11 \%$ in females, $N=12 ; 84 \pm 18 \%$ in males, $N=4$; NS by unpaired $t$ test).

To ascertain that the breathing response evoked by raphe photostimulation was at least partly attributable to the release of serotonin, we administered the broad spectrum serotonin receptor antagonist methysergide ( $5 \mathrm{mg} / \mathrm{kg}$, i.p.) to nine mice. This drug had no effect on resting dEMG amplitude $(99.0 \pm 3.1 \%$ of predrug level; $p=0.751$ ) but reduced the increase in dEMG amplitude produced by raphe stimulation by more than half on average (range, $-12 \%$ denoting an inhibitory response, to $57 \%$ of control response; median, $45.5 \%$; $p=0.04$ with Wilcoxon's signed rank test). The increase in frequency evoked by raphe stimulation was attenuated to a similar degree $(63.4 \pm 17 \%$ reduction relative to control response) by methysergide (from $35.4 \pm 9.5 \mathrm{~min}^{-1}$, range $8-85$, to $13.1 \pm 6.2 \mathrm{~min}^{-1}$, range -21 to $+35 ; p=0.015$ by parametric paired $t$ test). On average, methysergide had no effect on the baseline respiratory frequency (from $151 \pm 13$ to150 $\pm 14 \mathrm{~min}^{-1} ; N=8 ; p=0.937$ by paired $t$ test). A typical response to methysergide (eight of nine cases) is shown in Figure $4 A$. The atypical response in which the activation of breathing changed to inhibition after administration of methysergide is shown in Figure $4 B$.

To determine whether raphe serotonergic neurons potentiate the central respiratory chemoreflex, we stimulated ChR2transfected raphe neurons at rest and repeated the challenge while $8 \% \mathrm{CO}_{2}$ was added to the hyperoxic breathing mixture in

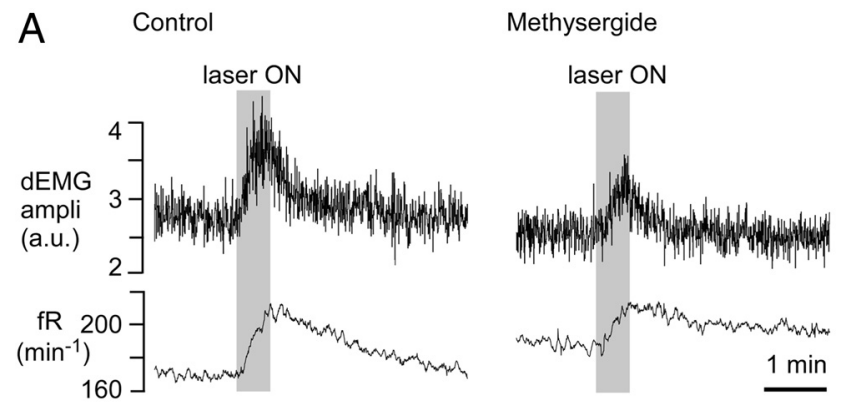

B

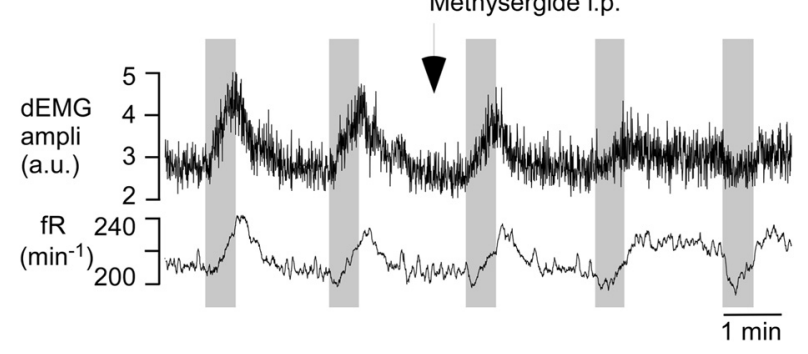

Figure 4. Breathing response elicited by raphe obscurus photostimulation: attenuation by the serotonin receptor antagonist methysergide. $\boldsymbol{A}$, In a typical case, $5 \mathrm{~min}$ after intraperitoneal administration of methysergide ( $5 \mathrm{mg} / \mathrm{kg}$ ), the amplitude (ampli), in arbitrary units (a.u.), and the frequency responses were decreased by about one-half. $\boldsymbol{B}$, Exceptional case in which the excitatory response to methysergide (same dose) was converted to inhibition. In either case, baseline parameters were only marginally affected by the drug.

11 mice. Hyperoxic hypercapnia increased baseline breathing parameters as expected (Fig. 5A,B). In each mouse except one, photostimulation of the raphe produced a greater increase in dEMG amplitude in the presence of added $\mathrm{CO}_{2}$ (Fig. $5 \mathrm{~A}$, representative example; $C$, group data). On average, the dEMG amplitude response was significantly larger during $\mathrm{CO}_{2}$ administration (Fig. $5 C)$. However, the baseline amplitude was also increased by $\mathrm{CO}_{2}$ (Fig. $5 A, B$ ), and when the response elicited by raphe stimulation was expressed as a percentage of this increased baseline (Fig. $5 C$, hi $\left.\mathrm{CO}_{2}{ }^{\#}\right)$, it was no longer significantly different from the response observed before $\mathrm{CO}_{2}$ administration. In short, on average, $\mathrm{CO}_{2}$ potentiated the dEMG amplitude response to raphe stimulation approximately in proportion to the change in baseline amplitude caused by activation of central chemoreceptors.

The frequency response to raphe stimulation was not potentiated by $\mathrm{CO}_{2}$ but tended to decrease slightly when expressed as a percentage of the elevated baseline during $\mathrm{CO}_{2}$ administration (Fig. 5D). The effect of raphe stimulation on the double product (fR by dEMG amplitude) was significantly potentiated by hypercapnia (increase relative to the resting baseline before $\mathrm{CO}_{2}$ administration, $73.5 \pm 12.7$ vs $63.1 \pm 13.2 \%$; $p<0.05$ by paired $t$ test). In other words, raphe stimulation produced a $16 \%$ larger increment in overall inspiratory effort at elevated levels of $\mathrm{CO}_{2}$, which was caused solely by a potentiation of the amplitude response in this model. This potentiation was significant only when the response was compared to that in the absence of added $\mathrm{CO}_{2}$. The difference disappeared when the response to raphe stimulation was expressed as a percentage of the elevated resting double product (fR by dEMG amplitude) measured during the administration of $\mathrm{CO}_{2}(63.1 \pm 13.2$ vs $60.1 \pm 10 \%$; NS by paired $t$ test $)$.

\section{Response of raphe neurons to pulses of laser light}

The midline medulla oblongata was explored in five ePet-Cre mice that had been injected with floxed ChR2-AAV2, and 19 
A

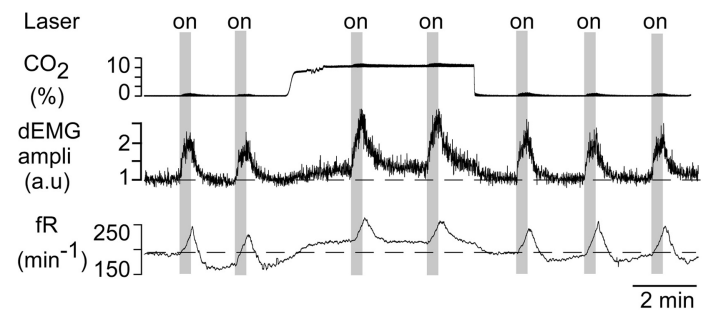

B

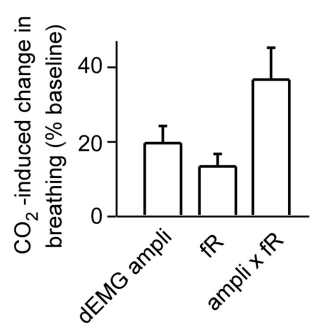

C

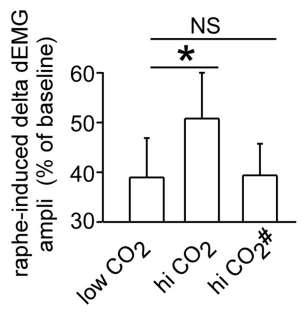

D

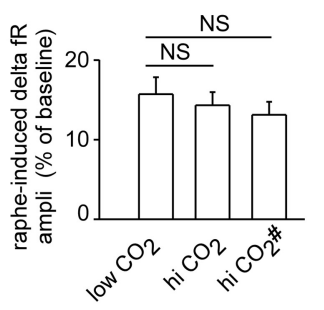

Figure 5. Hypercapnia potentiates the breathing response elicited by raphe obscurus photostimulation. A, A representative example showing responses to photostimulation applied for $20 \mathrm{~s}$ (gray "on" vertical bars) using 20 ms pulses at $10 \mathrm{~Hz}$. Eight percent $\mathrm{CO}_{2}$ was added to the breathing mixture where indicated in the top trace. dEMG amplitude (ampli) is presented in arbitrary units (a.u.). $\boldsymbol{B}$, Effect of $\mathrm{CO}_{2}$ on baseline parameters expressed as percent increase over resting values observed before the addition of $\mathrm{CO}_{2}$. $\boldsymbol{C}$, Increase in dEMG amplitude elicited by raphe obscurus stimulation (average of 11 mice). Left bar, Response to raphe stimulation observed without added $\mathrm{CO}_{2}$ and expressed as a percentage of resting value. Middle bar (hi $\left.\mathrm{CO}_{2}\right)$, Response in the presence of added $\mathrm{CO}_{2}$ and expressed as a percentage of the resting value before adding $\mathrm{CO}_{2}\left({ }^{*} p<0.05\right.$ when compared to values without $\mathrm{CO}_{2}$ added). Right bar (hi $\left.\mathrm{CO}_{2}{ }^{\#}\right)$, Response in the presence of added $\mathrm{CO}_{2}$ expressed as a percentage of the resting value observed in the presence of added $\mathrm{CO}_{2}$. D, Effect of $\mathrm{CO}_{2}$ on the increase in respiratory frequency caused by raphe obscurus stimulation. The three bars correspond to the same conditions as in $\boldsymbol{C}$.

neurons were identified that were activated on a pulse-by-pulse basis by laser light (Fig. 6A). These neurons were only encountered within $0.1 \mathrm{~mm}$ of the midline at a depth of between 5 and $5.8 \mathrm{~mm}$ below the cerebellar surface corresponding to the location of raphe obscurus. Of these 19 cells, 11 were tonically active with temporally stable discharge rates of $2.1 \pm$ 0.4 spikes per second (range, 0.1-4.4), and the rest were silent. The latter were encountered by slowly moving the recording electrode through the raphe while continually delivering $5 \mathrm{~ms}$ laser pulses at $2 \mathrm{~Hz}$. The photoactivated neurons were interspersed with photoinsensitive neurons that had similarly slow and temporally invariant discharge characteristics $(N=9$; discharge rate, $1.3 \pm 0.2$ spikes per second; range, 0.6-2.8).

The neuron shown in Figure $6 A$ is representative of the population of photoactivated raphe neurons. This cell had a steady regular discharge of 1.9 spikes per second. It was instantly entrained by the laser pulses to the precise frequency of the pulse train $(20 \mathrm{~Hz})$ and continued discharging at this rate until the end of the $30 \mathrm{~s}$ train. The neuron produced a single action potential per $20 \mathrm{~ms}$ light pulse, as was the case of 16 of the 19 photoactivated raphe cells. Its activity stopped immediately after the last light pulse and remained silent for another $35 \mathrm{~s}$ before resuming its normal discharge. The instant on-instant off activation of this and all other photoactivated raphe neurons contrasted sharply with the gradual rise and slow offset of the simultaneously recorded respiratory response (Fig. $6 A_{1}$ ). The pattern of activation during the train of stimuli was also highly representative of the 19 photoactivated neurons (Fig. $6 B)$. The latency of the action potential evoked by the first light pulse was shortest (1.3 ms) (Fig. 6B, arrowhead). This latency quickly increased within the next few pulses to reach $4 \mathrm{~ms}$ and changed very little during the next 596 pulses. All 19 neurons could be entrained at $20 \mathrm{~Hz}$ with $20 \mathrm{~ms}$ pulses. Many could also spike doublet.
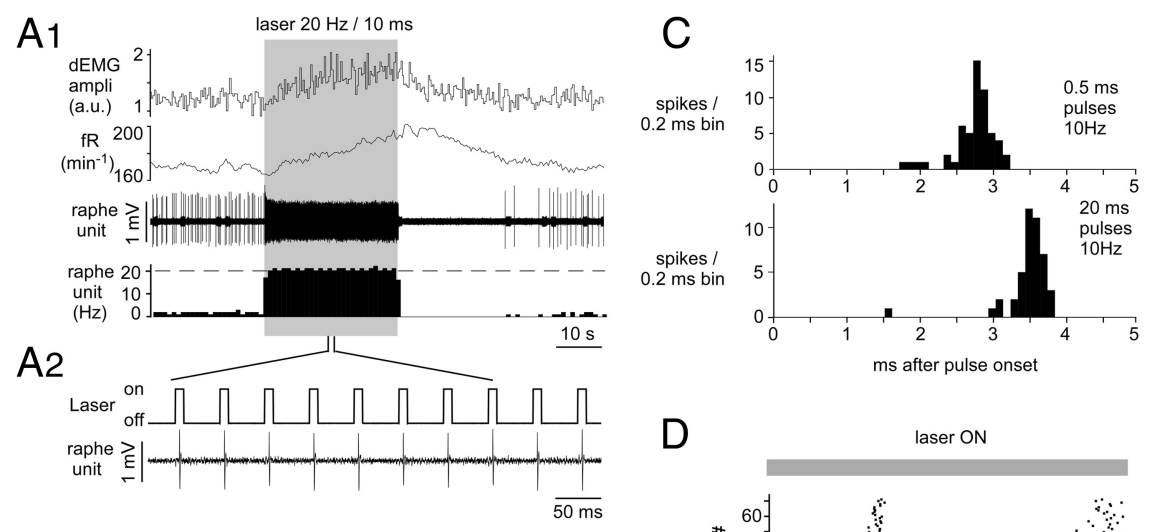

D
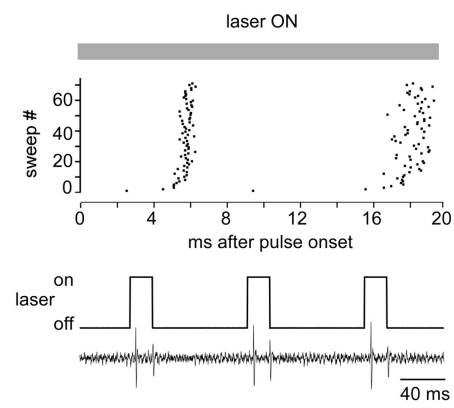

Figure 6. Responses of single raphe obscurus serotonergic neurons to light pulses. $A_{1}$, A representative example of a slowly active serotonergic neuron that was continually activated by a $30 \mathrm{~s}$ train of $10 \mathrm{~ms}$ pulses at $20 \mathrm{~Hz}$. From top to bottom, amplitude of dEMG bursts (in arbitrary units), breathing frequency, and raphe single-unit and integrated rate histograms of the same unit (1 $s$ bins) are shown. The onset of the breathing response was delayed by several seconds and increased gradually, whereas the neuron instantly reached its imposed frequency of $20 \mathrm{~Hz}$. The neuron stopped firing immediately after the last light pulse and remained silent for $>30 \mathrm{~s}$ before resuming its normal activity. $A_{2}$. High-resolution excerpt showing the faithful pulse-by-pulse entrainment of the neuron. $\boldsymbol{B}$. Raster and integrated rate histogram displays of the action potentials elicited by the light pulses in the neuron shown in $\boldsymbol{A}$. The trigger (time 0 ) was the onset of the $20 \mathrm{~ms}$ light pulses. The first evoked spike occurred $1.3 \mathrm{~ms}$ after light onset (arrow). This delay increased to about $4 \mathrm{~ms}$ within a few stimuli and thereafter remained approximately constant throughout the $30 \mathrm{~s}$ train of stimuli. C. Effect of light pulse duration (top, $0.5 \mathrm{~ms}$; bottom, $20 \mathrm{~ms}$ ) on action potential entrainment in a different serotonergic neuron. Histograms were triggered by the onset of the light pulses. D. Neuron in which $20 \mathrm{~ms}$ light pulses evoked a

follow shorter light pulses ( $<5 \mathrm{~ms}$ ) at $40 \mathrm{~Hz}$, but the amplitude of the action potentials tended to decrease greatly, presumably the consequence of excessive depolarization and sodium channel inactivation.

The pulse duration required to entrain the photoactivated neurons was determined in 15 neurons. All but two were activated on a pulse-by-pulse basis by light pulses of $1 \mathrm{~ms}$ duration or less with thresholds as low as $0.1 \mathrm{~ms}$ in four cases. The action potential occurred 1.4 to $8 \mathrm{~ms}$ after the onset of the light pulse even when the neuron responded faithfully to submillisecond 
A1

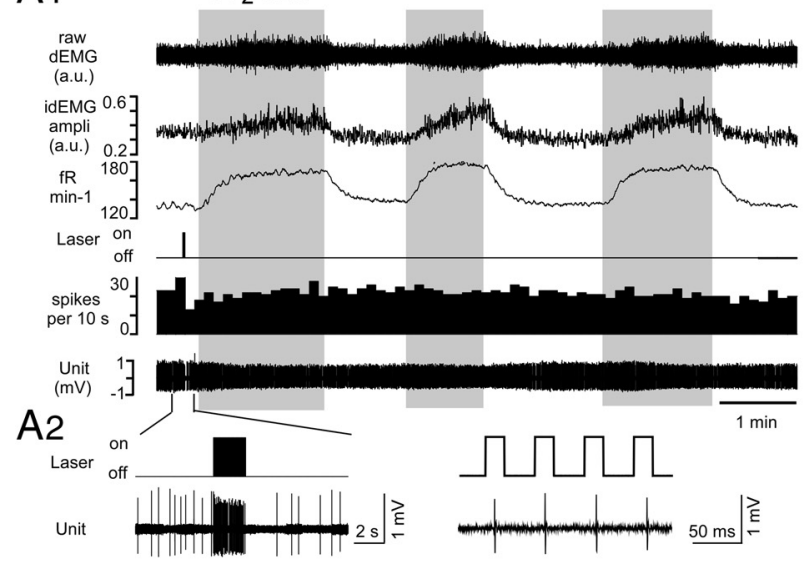

Figure 7. Hypercapnia increases breathing but does not change raphe obscurus unit activity. $A_{1}, A_{2}$, In a representative experiment, the unit was identified as serotonergic based on its pulse by pulse activation by laser light (higher-resolution excerpt in $\left.A_{2}\right)$. The mouse was exposed three successive times to hypercapnia ( $10 \% \mathrm{CO}_{2}$; times, gray bars) for long enough to observe a steady-state increase in respiratory frequency and amplitude (ampli), in arbitrary units (a.u.) (top three traces). $\boldsymbol{B}$, Average effect of hypercapnia in 11 light-activated serotonergic neurons (asterisk denotes very small but statistically significant reduction in discharge rate by ANOVA on rank). C, Typical absence of respiratory modulation in a representative raphe obscurus serotonergic neuron. The perievent activity histogram was triggered on the ascending phase of the diaphragm EMG (at arrow). The histogram is flat, indicating that the probability of discharge of the unit was the same throughout the respiratory cycle. The dotted line is the averaged diaphragm EMG burst event averaged from the same trigger point as the activity histogram.

light pulses. As illustrated in Figure 6C, the pulse duration had relatively little influence on the latency of the action potential relative to the pulse onset. This representative example shows the action potentials being evoked on average $2.8 \mathrm{~ms}$ after the onset of $0.5 \mathrm{~ms}$ pulses and $3.5 \mathrm{~ms}$ after the onset of $20 \mathrm{~ms}$ pulses.

Although the majority of the neurons responded to light by a single action potential regardless of pulse duration (up to $20 \mathrm{~ms}$ ), we encountered three exceptions. Two cells fired doublets (Fig. $6 D$ ) and one fired triplets in response to $20 \mathrm{~ms}$ pulses. These rare exceptions probably accounted for the relatively small increase in respiratory response produced by using pulses longer than $1 \mathrm{~ms}$ (Fig. 3B). In this subset of neurons, the depolarization mediated by ChR2 may have been strong enough to overcome the powerful hyperpolarization common to serotonergic neurons. Alternately, these neurons could also be a subset of serotonergic cells with uncommon intrinsic properties.

Strong nociceptive stimuli applied to the tail or hind legs produced a weak activation of a majority of the light-activated raphe neurons thus tested (seven of eight) consisting of one or a maximum of three spikes (data not shown). For ethical reasons, these tests were performed using a level of anesthesia at which a barely perceptible increase in respiratory frequency $\left(<5 \mathrm{~min}^{-1}\right)$ was elicited by the stimulus. These responses suggested that the serotonergic cells are activated by nociceptive stimuli but these tests did not provide a reliable estimate of the strength of the nociceptive inputs.

\section{Raphe obscurus serotonergic neurons are not respiratory} modulated and do not respond to hyperoxic hypercapnia The sensitivity of raphe obscurus neurons to increases in brain $\mathrm{PCO}_{2}$ was examined by adding up to $10 \% \mathrm{CO}_{2}$ to the hyperoxic breathing mixture for two to $3 \mathrm{~min}$, i.e., until the increase in dEMG amplitude and respiratory rate had reached a steady state (Fig. 7A). The $\mathrm{CO}_{2}$ stimulus was repeated two to three times per cell to ascertain the stability of the recording and the reproducibility of the effect. The test was performed in three males and one female on the 11 spontaneously active, light-entrained neurons
B

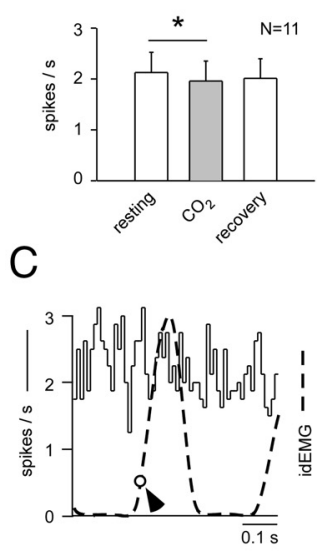

(two, three, and four neurons each recorded in three males; two neurons recorded in one female) and on the nine comingled, slowly active, photoinsensitive raphe neurons found in the same mice (two and three neurons in two males; four neurons in one female) that are likely to have also been serotonergic neurons.

$\mathrm{CO}_{2}$ increased the frequency and amplitude of the dEMG as expected, but the photosensitive cells did not respond to hypercapnia (Fig. 7A). The group data are shown in Figure $7 B$. A nonparametric ANOVA revealed that the neurons were discharging at a statistically significant lower rate during $\mathrm{CO}_{2}$ administration, although the reduction was objectively negligible (median of 2.3 spikes per second before and after $\mathrm{CO}_{2} ; 2.2$ spikes per second during $\mathrm{CO}_{2}$ administration). Neurons appeared equally insensitive to $\mathrm{CO}_{2}$ in males and females, although statistics could not be applied to prove this assertion given the skewed distribution of the recorded neurons among males and females.

The nine slowly active and photoinsensitive raphe neurons recorded in the immediate vicinity of the photoactivated cells were unaffected by hyperoxic hypercapnia $(1.28 \pm 0.25$ spikes per second before $\mathrm{CO}_{2} ; 1.17 \pm 0.25$ in the presence of $\mathrm{CO}_{2}$; $1.22 \pm 0.19$ after recovery from $\mathrm{CO}_{2} ; p=0.39$ by one-way ANOVA).

Perievent activity histograms triggered by the dEMG were obtained for 10 of the 11 photoactivated raphe neurons and eight of the nine comingled serotonergic-like raphe neurons (Fig. 7C). This analysis was designed to test whether the cells received any synaptic input from the central respiratory pattern generator and was motivated by previous observations that raphe obscurus neurons receive such inputs (Gilbey et al., 1995; Ptak et al., 2009). In all cases, the perievent histograms were flat, indicating that, under our experimental conditions, raphe obscurus serotonergic neurons did not receive detectable synaptic inputs from the respiratory network.

\section{Discussion}

We demonstrate that activation of raphe obscurus serotonergic neurons stimulates breathing, and we provide the first definitive recordings of raphe obscurus serotonergic neurons in vivo. We show that these neurons potentiate the respiratory chemoreflex but do not respond to $\mathrm{CO}_{2}$. Thus, raphe obscurus serotonergic neurons regulate breathing but are not central respiratory chemoreceptors.

Raphe obscurus serotonergic neurons have multiple targets The entire ventrolateral medulla, not just the respiratory rhythmgenerating region (Tan et al., 2008), was innervated by raphe obscurus. Spinal and medullary regions primarily involved in sensory function were not targeted, consistent with previous evidence that they are innervated by raphe magnus (Mason, 2001). Based on its projection pattern, raphe obscurus seems primarily involved in somatic and autonomic motor control, consistent with the facilitatory effect of serotonin on locomotion (Liu et al., 2009; Klein et al., 2010) and evidence that the discharge of raphe 
obscurus neurons correlates with somatic motor activity in cats (Jacobs et al., 2002). The multiple targets of raphe obscurus revealed by our method are not surprising (Loewy, 1981; Skagerberg and Bjorklund, 1985; Thor and Helke, 1987; Ellenberger and Feldman, 1990; Hornby et al., 1990) and emphasize that raphe obscurus serotonergic neurons must be regulating a vastly larger population of neurons than those involved in respiration. Whether individual raphe obscurus serotonergic neurons have narrowly specialized targets and functions or broadly innervate neurons implicated in somatic and autonomic functions is unknown.

\section{In vivo identification of raphe obscurus serotonergic neurons by channelrhodopsin-2 optogenetics}

Cre recombinase is expressed exclusively in serotonergic neurons in ePet-Cre mice (Scott et al., 2005). As expected, ChR2 was selectively present $(\sim 97 \%)$ in serotonergic neurons after injection of AAV2 DIO ChR2-mCherry. To identify the serotonergic neurons, we took advantage of the diagnostic entrainment of ChR2-transfected neurons to short pulses of laser light (Nagel et al., 2003; Boyden et al., 2005; Abbott et al., 2009b; Lima et al., 2009).

Consistent with the histology, photoactivatable neurons were found in the midline and were absent from immediately adjacent regions. Action potentials elicited by submillisecond light pulses occurred 2-3 ms after pulse onset, which could represent the antidromic latency of action potentials triggered in axons (Cruikshank et al., 2010) or the photoactivation kinetics of somatodendritic ChR2 (Bamann et al., 2008).

\section{Control of breathing by raphe obscurus serotonergic neurons} The majority of ChR2-transfected neurons were in raphe obscurus; therefore, the breathing stimulation probably resulted from activating this structure rather than the underlying raphe pallidus. The breathing stimulation is consistent with the excitatory effect of serotonin on phrenic motor neurons and many brainstem respiratory neurons, including the retrotrapezoid nucleus (Holtman et al., 1986, 1987; Lindsay and Feldman, 1993; Peña and Ramirez, 2002; Mulkey et al., 2007). Our observations extend previous evidence that glutamate injection into raphe obscurus activates breathing (Ptak et al., 2009; Doi and Ramirez, 2010). Also extending previous work (Holtman et al., 1986; Ptak et al., 2009), we found that blockade of 5HT-2 receptors always attenuated the respiratory stimulation caused by raphe stimulation. Therefore, we demonstrate that the methysergide-resistant breathing stimulation is indeed caused by activating serotonergic neurons. This residual effect must be mediated by methysergideinsensitive serotonergic receptors (5HT4, 5HT1A) (Manzke et al., 2003, 2009; Ptak et al., 2009) or by other transmitters released by serotonergic neurons (Thor and Helke, 1989; Li et al., 2005; Ptak et al., 2009).

Methysergide did not change basal breathing parameters in our mice, consistent with the low resting discharge of serotonergic neurons $(0-2 \mathrm{~Hz})$ and the fact that serotonergic neurons had to be activated at $2 \mathrm{~Hz}$ to elicit a threshold respiratory response. The contribution of serotonergic neurons to the basal activity of the respiratory controller evidently varies between preparations (Peña and Ramirez, 2002; Ptak et al., 2009) and remains to be assessed in conscious animals.

Serotonergic neurons were faithfully entrained by the laser pulses and no afterdischarge was observed. Therefore, the slow relaxation kinetics of the breathing response reflects the long intracellular half-life of the second messenger systems triggered by serotonin receptors (Doi and Ramirez, 2010) or some intrinsic property of the respiratory network. Indeed a similarly slow off rate has been observed after stimulation of retrotrapezoid chemoreceptors (Abbott et al., 2009b), which are probably glutamatergic (Mulkey et al., 2004). The slow onset and offset kinetics may also reflect the time required for serotonin to reach a critical extracellular concentration and then clear the extracellular space after the stimulus.

\section{Central respiratory chemosensitivity: role of the serotonergic system}

There is oft-reviewed evidence that serotonergic neurons are central chemoreceptors (Nattie and Li, 2008; Hodges and Richerson, 2010). Serotonergic neurons respond to acidification in vitro, mice born without serotonergic neurons have attenuated respiratory responses to hypercapnia, and, in one study, serotonin release was found to increase in response to $\mathrm{CO}_{2}$ (Hodges and Richerson, 2010). This evidence is not conclusive proof that serotonergic neurons function as central respiratory chemoreceptors (Guyenet et al., 2010), especially because raphe serotonergic neurons may receive excitatory inputs from the respiratory centers and derive their response to $\mathrm{CO}_{2}$ from these inputs (Ptak et al., 2009).

Our contention is that if serotonergic neurons are chemoreceptors, they should respond to hypercapnia under all experimental conditions just like other documented central chemoreceptors (Guyenet et al., 2010). Clearly, the serotonergic neurons of the parapyramidal region do not respond to $\mathrm{CO}_{2}$ (Mulkey et al., 2004), but they could be an exception to the proposed rule that serotonergic neurons are " $\mathrm{CO}_{2}$ detectors" (Richerson, 2004). As directly shown here and suggested previously (Hodges et al., 2004; Nattie and Li, 2009; Hodges and Richerson, 2010) raphe obscurus undoubtedly regulates breathing. Yet, again, the raphe obscurus serotonergic neurons did not respond to hyperoxic hypercapnia, although this stimulus produced the expected increase in breathing rate and amplitude. The recorded serotonergic neurons had a very low level of activity and had no active input from the respiratory centers. Both conditions were thus highly favorable to detect even a small direct stimulatory effect of hypercapnia, had such an effect existed. An artifact caused by ChR2 transfection can be excluded because retrotrapezoid neurons transfected with ChR2 retain their $\mathrm{CO}_{2}$ sensitivity in vivo (Abbott et al., 2009b), and active but untransfected raphe obscurus neurons that were comingled with the transfected serotonergic neurons were equally insensitive to hypercapnia. Our negative results extend prior evidence that the vast majority of "serotonin-like" raphe obscurus units were insensitive to hypercapnia in conscious cats (Veasey et al., 1995). The few feline neurons that responded during the waking state no longer did so during sleep, implying that their activation by $\mathrm{CO}_{2}$ was most likely behavior related.

Isoflurane does not change the $\mathrm{CO}_{2}$ /acid sensitivity of the central respiratory chemoreceptors located in the retrotrapezoid nucleus (Lazarenko et al., 2010) and has no effect on the pHdependent release of ATP by marginal glia, which mediates the $\mathrm{CO}_{2}$ sensitivity of these neurons (Gourine et al., 2010). Isoflurane could conceivably depress the chemosensitivity of the serotonergic neurons selectively, thereby explaining our negative results. Alternately, we could have failed to record from the still elusive minority of serotonergic neurons that are $\mathrm{CO}_{2}$ responsive.

Serotonergic neurons are assumed to detect $\mathrm{CO}_{2}$ via a cellautonomous sensitivity to acid (Hodges and Richerson, 2010). However, their acid sensitivity is only notable in culture (Wang et al., 2001; Bouyer et al., 2004). It is inconsistent in slices (Corcoran 
et al., 2009), and these cells do not respond to hypercapnia in vivo in anesthetized animals (Mulkey et al., 2004; present study). The key to these contradictory findings may be the degree of integrity of the glial environment, poor in slices, poorest in cultures, and possibly damaged by dialysis probes (Dias et al., 2008; Nattie and $\mathrm{Li}, 2009)$. The fact that isolated neurons respond to acid is considered prime evidence that these cells must be responsive to changes in arterial $\mathrm{PCO}_{2}$ in vivo (Hodges and Richerson, 2010). Since the response of retrotrapezoid neurons to $\mathrm{CO}_{2}$ is apparently not a cell-autonomous property but relies instead on a specialized form of $\mathrm{pH}$-sensitive glia, the argument is no longer compelling (Erlichman et al., 2008; Gourine et al., 2010). The lack of effect of $\mathrm{CO}_{2}$ on serotonergic neurons in vivo may denote the fact that, outside very specific brainstem regions, glial cells buffer extracellular brain $\mathrm{pH}$ when arterial $\mathrm{PCO}_{2}$ rises. This concept is also supported by evidence that brain acidification varies considerably from region to region in response to a given change in arterial $\mathrm{PCO}_{2}$ (Arita et al., 1989).

In conclusion, the projections of raphe obscurus serotonergic neurons suggest that these neurons target multiple autonomic outflows in addition to contributing to somatic motor control and breathing. We found no evidence that these serotonergic neurons detect changes in $\mathrm{PCO}_{2}$ in vivo, but these neurons evidently regulate the breathing network and do potentiate the chemoreflex. This potentiation likely denotes the ability of serotonergic neurons to facilitate the response of the respiratory network to $\mathrm{CO}_{2}$-dependent excitatory drives generated elsewhere. The important role of serotonergic neurons in breathing and their putative contribution to respiratory pathologies such as sudden infant death syndrome (Duncan et al., 2010) clearly does not require that these neurons be directly responsive to $\mathrm{CO}_{2}$.

\section{References}

Abbott SB, Stornetta RL, Socolovsky CS, West GH, Guyenet PG (2009a) Photostimulation of channelrhodopsin-2 expressing ventrolateral medullary neurons increases sympathetic nerve activity and blood pressure in rats. J Physiol 587:5613-5631.

Abbott SB, Stornetta RL, Fortuna MG, Depuy SD, West GH, Harris TE, Guyenet PG (2009b) Photostimulation of retrotrapezoid nucleus Phox $2 \mathrm{~b}$-expressing neurons in vivo produces long-lasting activation of breathing in rats. J Neurosci 29:5806-5819.

Arita H, Ichikawa K, Kuwana S, Kogo N (1989) Possible locations of pHdependent central chemoreceptors: intramedullary regions with acidic shift of extracellular fluid pH during hypercapnia. Brain Res 485:285-293.

Bamann C, Kirsch T, Nagel G, Bamberg E (2008) Spectral characteristics of the photocycle of channelrhodopsin-2 and its implication for channel function. J Mol Biol 375:686-694.

Bouyer P, Bradley SR, Zhao J, Wang W, Richerson GB, Boron WF (2004) Effect of extracellular acid-base disturbances on the intracellular $\mathrm{pH}$ of neurons cultured from rat medullary raphe or hippocampus. J Physiol 558:85-101.

Boyden ES, Zhang F, Bamberg E, Nagel G, Deisseroth K (2005) Millisecondtimescale, genetically targeted optical control of neural activity. Nat Neurosci 8:1263-1268.

Cardin JA, Carlen M, Meletis K, Knoblich U, Zhang F, Deisseroth K, Tsai LH, Moore CI (2009) Driving fast-spiking cells induces gamma rhythm and controls sensory responses. Nature 459:663-667.

Cardin JA, Carlen M, Meletis K, Knoblich U, Zhang F, Deisseroth K, Tsai LH, Moore CI (2010) Targeted optogenetic stimulation and recording of neurons in vivo using cell-type-specific expression of Channelrhodopsin-2. Nat Protoc 5:247-254.

Corcoran AE, Hodges MR, Wu Y, Wang W, Wylie CJ, Deneris ES, Richerson GB (2009) Medullary serotonin neurons and central CO2 chemoreception. Respir Physiol Neurobiol 168:49-58.

Cruikshank SJ, Urabe H, Nurmikko AV, Connors BW (2010) Pathwayspecific feedforward circuits between thalamus and neocortex revealed by selective optical stimulation of axons. Neuron 65:230-245.

Dias MB, Li A, Nattie EE (2008) Focal CO2 dialysis in raphe obscurus (ROb) does not stimulate ventilation but enhances the response to focal $\mathrm{CO} 2$ dialysis in the retrotrapezoid nucleus (RTN). J Appl Physiol 105:83-90.

Doi A, Ramirez JM (2010) State-dependent interactions between excitatory neuromodulators in the neuronal control of breathing. J Neurosci 30:8251-8262.

Duncan JR, Paterson DS, Hoffman JM, Mokler DJ, Borenstein NS, Belliveau RA, Krous HF, Haas EA, Stanley C, Nattie EE, Trachtenberg FL, Kinney HC (2010) Brainstem serotonergic deficiency in sudden infant death syndrome. JAMA 303:430-437.

Ellenberger HH, Feldman JL (1990) Brainstem connections of the rostral ventral respiratory group of the rat. Brain Res 513:35-42.

Erlichman JS, Putnam RW, Leiter JC (2008) Glial modulation of CO2 chemosensory excitability in the retrotrapezoid nucleus of rodents. Adv Exp Med Biol 605:317-321.

Gilbey MP, Futuro-Neto HA, Zhou SY (1995) Respiratory-related discharge patterns of caudal raphe neurones projecting to the upper thoracic spinal cord in the rat. J Auton Nerv Syst 50:263-273.

Gourine AV, Kasymov V, Marina N, Tang F, Figueiredo MF, Lane S, Teschemacher AG, Spyer KM, Deisseroth K, Kasparov S (2010) Astrocytes control breathing through $\mathrm{pH}$-dependent release of ATP. Science 329:571-575.

Gradinaru V, Zhang F, Ramakrishnan C, Mattis J, Prakash R, Diester I, Goshen I, Thompson KR, Deisseroth K (2010) Molecular and cellular approaches for diversifying and extending optogenetics. Cell 141:154-165.

Guyenet PG, Mulkey DK, Stornetta RL, Bayliss DA (2005) Regulation of ventral surface chemoreceptors by the central respiratory pattern generator. J Neurosci 25:8938-8947.

Guyenet PG, Stornetta RL, Bayliss DA (2010) Central respiratory chemoreception. J Comp Neurol 518:3883-3906.

Hodges MR, Richerson GB (2010) The role of medullary serotonin (5-HT) neurons in respiratory control: contributions to eupneic ventilation, $\mathrm{CO} 2$ chemoreception, and thermoregulation. J Appl Physiol 108:1425-1432.

Hodges MR, Martino P, Davis S, Opansky C, Pan LG, Forster HV (2004) Effects on breathing of focal acidosis at multiple medullary raphe sites in awake goats. J Appl Physiol 97:2303-2309.

Holtman JF, Dick TE, Berger AJ (1987) Serotonin-mediated excitation of recurrent laryngeal and phrenic motoneurons evoked by stimulation of the raphe obscurus. Brain Res 417:12-20.

Holtman JR, Dick TE, Berger AJ (1986) Involvement of serotonin in the excitation of phrenic motoneurons evoked by stimulation of the raphe obscurus. J Neurosci 6:1185-1193.

Hornby PJ, Rossiter CD, White RL, Norman WP, Kuhn DH, Gillis RA (1990) Medullary raphe: a new site for vagally mediated stimulation of gastric motility in cats. AJP 258:G637-G647.

Jacobs BL, Martin-Cora FJ, Fornal CA (2002) Activity of medullary serotonergic neurons in freely moving animals. Brain Res Brain Res Rev 40:45-52.

Klein DA, Patino A, Tresch MC (2010) Flexibility of motor pattern generation across stimulation conditions by the neonatal rat spinal cord. J Neurophysiol 103:1580-1590.

Lazarenko RM, Fortuna MG, Shi Y, Mulkey DK, Takakura AC, Moreira TS, Guyenet PG, Bayliss DA (2010) Anesthetic activation of central respiratory chemoreceptor neurons involves inhibition of a THIK-1-like background $\mathrm{K}(+)$ current. J Neurosci 30:9324-9334.

Li Q, Goodchild AK, Seyedabadi M, Pilowsky PM (2005) Pre-protachykinin A mRNA is colocalized with tyrosine hydroxylase-immunoreactivity in bulbospinal neurons. Neurosci 136:205-216.

Lima SQ, Hromadka T, Znamenskiy P, Zador AM (2009) PINP: a new method of tagging neuronal populations for identification during in vivo electrophysiological recording. PLoS One 4:e6099.

Lindsay AD, Feldman JL (1993) Modulation of respiratory activity of neonatal rat phrenic motoneurones by serotonin. J Physiol 461:213-233.

Liu J, Akay T, Hedlund PB, Pearson KG, Jordan LM (2009) Spinal 5-HT7 receptors are critical for alternating activity during locomotion: in vitro neonatal and in vivo adult studies using 5-HT7 receptor knockout mice. J Neurophysiol 102:337-348.

Loewy AD (1981) Raphe pallidus and raphe obscurus projections to the intermediolateral cell column in the rat. Brain Res 222:129-133.

Madden CJ, Morrison SF (2006) Serotonin potentiates sympathetic responses evoked by spinal NMDA. J Physiol 577:525-537.

Manzke T, Guenther U, Ponimaskin EG, Haller M, Dutschmann M, Schwar- 
zacher S, Richter DW (2003) 5-HT4(a) receptors avert opioid-induced breathing depression without loss of analgesia. Science 301:226-229.

Manzke T, Dutschmann M, Schlaf G, Morschel M, Koch UR, Ponimaskin E, Bidon O, Lalley PM, Richter DW (2009) Serotonin targets inhibitory synapses to induce modulation of network functions. Philos Trans R Soc Lond B Biol Sci 364:2589-2602.

Mason P (2001) Contributions of the medullary raphe and ventromedial reticular region to pain modulation and other homeostatic functions 4142. Annu Rev Neurosci 24:737-777.

Mulkey DK, Stornetta RL, Weston MC, Simmons JR, Parker A, Bayliss DA, Guyenet PG (2004) Respiratory control by ventral surface chemoreceptor neurons in rats. Nat Neurosci 7:1360-1369.

Mulkey DK, Rosin DL, West G, Takakura AC, Moreira TS, Bayliss DA, Guyenet PG (2007) Serotonergic neurons activate chemosensitive retrotrapezoid nucleus neurons by a $\mathrm{pH}$-independent mechanism. J Neurosci 27:14128-14138.

Nagel G, Szellas T, Huhn W, Kateriya S, Adeishvili N, Berthold P, Ollig D, Hegemann P, Bamberg E (2003) Channelrhodopsin-2, a directly lightgated cation-selective membrane channel. Proc Natl Acad Sci U S A 100:13940-13945.

Nattie E, Li A (2009) Central chemoreception is a complex system function that involves multiple brain stem sites. J Appl Physiol 106:1464-1466.

Nattie EE, Li A (2008) Multiple central chemoreceptor sites: cell types and function in vivo. Adv Exp Med Biol 605:343-347.

Paxinos G, Franklin KB (2004) The mouse brain in stereotaxic coordinates. Amsterdam: Elsevier.

Peña F, Ramirez JM (2002) Endogenous activation of serotonin-2A receptors is required for respiratory rhythm generation in vitro. J Neurosci 22:11055-11064.

Ptak K, Yamanishi T, Aungst J, Milescu LS, Zhang R, Richerson GB, Smith JC (2009) Raphe neurons stimulate respiratory circuit activity by multiple mechanisms via endogenously released serotonin and substance P. J Neurosci 29:3720-3737.

Richerson GB (2004) Serotonergic neurons as carbon dioxide sensors that maintain pH homeostasis. Nat Rev Neurosci 5:449-461.

Scott MM, Wylie CJ, Lerch JK, Murphy R, Lobur K, Herlitze S, Jiang W, Conlon RA, Strowbridge BW, Deneris ES (2005) A genetic approach to access serotonin neurons for in vivo and in vitro studies. Proc Natl Acad Sci U S A 102:16472-16477.

Skagerberg G, Bjorklund A (1985) Topographic principles in the spinal projections of serotonergic and non-serotonergic brainstem neurons in the rat. Neurosci 15:445-480.

Stornetta RL, Sevigny CP, Schreihofer AM, Rosin DL, Guyenet PG (2002) Vesicular glutamate transporter DNPI/GLUT2 is expressed by both C1 adrenergic and nonaminergic presympathetic vasomotor neurons of the rat medulla. J Comp Neurol 444:207-220.

Tan W, Janczewski WA, Yang P, Shao XM, Callaway EM, Feldman JL (2008) Silencing preBotzinger Complex somatostatin-expressing neurons induces persistent apnea in awake rat. Nat Neurosci 11:538-540.

Thor KB, Helke CJ (1987) Serotonin- and substance P-containing projections to the nucleus tractus solitarii of the rat. J Comp Neurol 265:275-293.

Thor KB, Helke CJ (1989) Serotonin and substance P colocalization in medullary projections to the nucleus tractus solitarius: dual-colour immunohistochemistry combined with retrograde tracing. J Chem Neuroanat 2:139-148.

Veasey SC, Fornal CA, Metzler CW, Jacobs BL (1995) Response of serotonergic caudal raphe neurons in relation to specific motor activities in freely moving cats. J Neurosci 15:5346-5359.

Wang WG, Tiwari JK, Bradley SR, Zaykin AV, Richerson GB (2001) Acidosis-stimulated neurons of the medullary raphe are serotonergic. J Neurophysiol 85:2224-2235.

Zhang F, Wang LP, Boyden ES, Deisseroth K (2006) Channelrhodopsin-2 and optical control of excitable cells. Nat Methods 3:785-792. 